\title{
FEM analysis of dynamic flexural behaviour of composite sandwich beams with foam core
}

\author{
Inés Ivañez, Carlos Santiuste, Sonia Sanchez-Saez* \\ Department of Continuum Mechanics and Structural Analysis, Carlos III University of Madrid, Avda. Universidad, 30, 28911 Leganes, Spain
}

\section{A R T I C L E I N F O}

Keywords:

Composite sandwich beams

Numerical modelling

Dynamic bending tests

\begin{abstract}
A B S T R A C T
The dynamic flexural behaviour of sandwich beams, with composite face sheets and a foam core, was analysed by developing a 3D finite element model. To model the core behaviour, a crushable foam model was used. The Hou criteria were used to predict the failure of the face sheets. Dynamic bending tests were performed to validate the numerical model. The comparison between numerical and experimental results in terms of contact force histories, peak force values, absorbed energy, and maximum displace ment of both face sheets was satisfactory. It was revealed that the collapse of the foam core under the impact region favoured the failure of the upper face sheet.
\end{abstract}

\section{Introduction}

Sandwich beams with composite faces sheets and foam core are widely used as lightweight components in automotive, marine and aerospace applications due to high bending stiffness and strength combined with low weight. Therefore, it is important to gain knowledge of their flexural behaviour under static as well as dy namic loads.

Although extensive research has been devoted to the flexural behaviour of composite laminates in general [ 13 3], the flexural behaviour of sandwich structures is quite different. In this context, numerous works describe the static flexural behaviour of sandwich beams [4 8].

Several works treating the dynamic flexural behaviour of sand wich beams have also confirmed the marked susceptibility of sand wich structures to damage caused by the low velocity impact of foreign objects. Impacts can damage the face sheets, the core material, and the core face interface. The type of damage usually found in the faces is similar to that observed after impacts on monolithic composites. However, the damage initiation thresholds and damage area depend on the properties of the core material and the relationship between the properties of the core and those of the face sheets [9].

Many of these works involve experimental studies on the behaviour of polymer foam core sandwich structures [10 13 ]. The dynamic behaviour of beams depends on a large number of variables (e.g. geometry of the beams, impact features, material properties). To analyse experimentally the influence of these vari ables, numerous tests are needed. For reductions in the cost and

\footnotetext{
* Corresponding author.

E-mail address: ssanchez@ing.uc3m.es (S. Sanchez-Saez).
}

the time of such tests, it is essential to use theoretical models. A number of researchers have attempted to model analytically the dynamic flexural response of sandwich structures. Two different types of analytical models have been used, such as a mass spring model $[14,15]$ and an energy balance model [12,16], to predict the peak load and the load history of the structure. However, the analytical models include a large number of simplifications and assumptions and so, for more detailed analyses, most researchers use finite element simulations.

The performance of FEM simulations of sandwich beams and accurate descriptions of the damage induced by the contact area, require the modelling of both the face sheets as well as the core.

With respect to the composite laminate face sheets, specialised criteria which describe the occurrence of various failure modes and material degradation models that reduce stiffness properties were used. Steeves and Fleck [5] considered that the yield strength of the face sheets was attained only for the collapse mode of face micro buckling. They treated the face sheets as isotropic and elastic ide ally plastic material with their tensile and compressive strengths equal to the microbuckling strength. Mines and Alias [4] used the Hashin criterion and the Lee extended Hashin's arguments to con sider the modes of laminate failure (fibre breakage, matrix crack ing, and delamination) and three dimensional failure effects. Icardi and Ferrero [16] used the latest 3D version of the Hashin's criterion with in situ strengths to predict the failure of fibres and the matrix, and Choi Chang's criterion and an heuristic criterion for delamination. In monolithic laminates, one of the most com monly used criteria to predict the failure of laminates under dy namic conditions is the model developed by Chang Chang [17], which considers three damage mechanisms: fibre breakage, and tensile as well as compressive matrix cracking. Hou et al. [18] re vised this model, modifying the equations which describe each 
mechanism and adding a delamination criterion. Both models were developed for tape laminates, and similar models could be found in the literature for woven composites $[19,20]$.

For the foam core modelling, Steeves and Fleck [5] employed the polymer foam constitutive model of Deshpande and Fleck [21] which utilises a principal stress yield surface under compres sion and a quadratic yield surface elsewhere in the stress space. Mines and Alias [4] used a foam model based on critical state the ory with adjustments to take into account volumetric effects and a non associative flow rule. Icardi and Ferrero [16], considering the foam core to be a homogeneous isotropic material, used the Von Mises yield criterion. Sadighi and Pouriayevali [15] used a model of a crushable foam material which was validated by uniaxial com pression test results.

However, there is a lack of knowledge about the interaction be tween the failure of the core and the failure of the composite face sheets. This interaction is important because a sandwich beam subjected to a low velocity impact presents high stress levels in the core due to the contact force and, consequently, there is a col lapse of the foam located in the contact zone. This localised dam age can produce a failure of the upper face sheet and thereby reduce the strength of the sandwich beam, causing a possible unexpected failure of the structure.

The present work improves the knowledge of the failure of composite sandwich beams subjected to low velocity impacts. For a better understanding of the dynamic bending behaviour of sandwich beams with composite face sheets and foam core, a numerical model was developed. In order to evaluate the reliability of the numerical model, dynamic three point bending tests were carried out.

\section{Materials}

The sandwich face sheets were made up of plain woven lami nates of E glass fibres and polyester resin AROPOL FS6902. The thickness of the each face sheet was $3 \mathrm{~mm}$. The core consisted of PVC foam, with a nominal density and thickness of $100 \mathrm{~kg} / \mathrm{m}^{3}$ and $30 \mathrm{~mm}$, respectively. The use of these materials for sandwich structures is fairly widespread due to their energy absorption properties, which are usually greater than those of general elastic materials.

\subsection{Characterisation tests}

From characterisation tests, mechanical properties of the face sheets and core were determined. These properties were needed in order to develop the numerical model.

The mechanical properties of face sheet material are shown in Table 1.

To determine the behaviour of the core, flatwise compression tests were performed according to ASTM C 365/C365M 05 Stan dard. Five square specimens of $50 \times 50 \mathrm{~mm}$ and $30 \mathrm{~mm}$ thick were tested. Testing was conducted on a servohydraulic test machine, Instron 8516 , with loading rates of $0.5 \mathrm{~mm} / \mathrm{min}$ applied to speci

Table 1

Mechanical properties of face-sheet plies for the sandwich beam.

\begin{tabular}{ll}
\hline Density, $\rho$ & $1800 \mathrm{~kg} / \mathrm{m}^{3}$ \\
Young's modulus, $E_{1}=E_{2}$ & $10.1 \mathrm{GPa}$ \\
Poisson ratio, $v_{12}$ & 0.16 \\
In-plane shear modulus, $G_{12}$ & $3.1 \mathrm{GPa}$ \\
Interlaminar shear modulus, $G_{13}=G_{23}$ & $1.2 \mathrm{GPa}$ \\
Tensile strength, $X_{\mathrm{T}}=Y_{\mathrm{T}}$ & $367.4 \mathrm{MPa}$ \\
Compressive strength, $X_{c}=Y_{c}$ & $367.4 \mathrm{MPa}$ \\
Interlaminar shear strength, $S_{13}=S_{23}$ & $34.3 \mathrm{MPa}$ \\
Ultimate strain & $3.57 \%$ \\
\hline
\end{tabular}

mens via flat and parallel platens such that the load was distrib uted uniformly over the loading surfaces. The measured load versus displacement is plotted in Fig. 1.

\section{Numerical model}

A numerical model was developed to analyse the dynamic flex ural behaviour of composite foam core sandwich beams, using ABAQUS/Explicit code [22]. Beams of rectangular cross section (50 $\mathrm{mm}$ width and $36 \mathrm{~mm}$ thickness) and $480 \mathrm{~mm}$ length were considered. The face sheet behaviour was modelled through a user subroutine (VUMAT) which includes the Hou failure criteria [18] and a procedure to degrade material properties. The foam core was modelled as a crushable foam material for which the harden ing curve was determined from a foam compression test.

\subsection{Face sheet model}

The composite failure criteria proposed by Hou [18] include four failure modes: fibre failure, matrix cracking, matrix crushing, and delamination. Some modifications were made in the Hou mod el, since it was developed for tape plies and not for woven ones. The Hou model was developed to predict the failure of composite tape plies, in which fibres are oriented in a single direction. The matrix failure modes included in the Hou failure criteria consid ered that transverse stresses produce matrix failure. However, a woven laminate contains fibres in the transverse direction to support theses stresses. For this reason, in the present work, a fibre failure criterion was applied to $0^{\circ}$ and $90^{\circ}$ directions, both in tensile and compressive stresses [19]. The Brewer and Lagace failure criterion [23] was included in the subroutine formulation to model the delamination and was applied only to normal tensile stress $\left(\sigma_{33}>0\right)$.

Fibre failure:

$$
\begin{array}{ll}
d_{f 1}^{2} & \left(\frac{\sigma_{11}}{X_{t}}\right)^{2}+\left(\frac{\sigma_{12}^{2}+\sigma_{13}^{2}}{S_{12}^{2}}\right) \\
d_{f 2}^{2} & \left(\frac{\sigma_{22}}{Y_{t}}\right)^{2}+\left(\frac{\sigma_{12}^{2}+\sigma_{23}^{2}}{S_{12}^{2}}\right)
\end{array}
$$

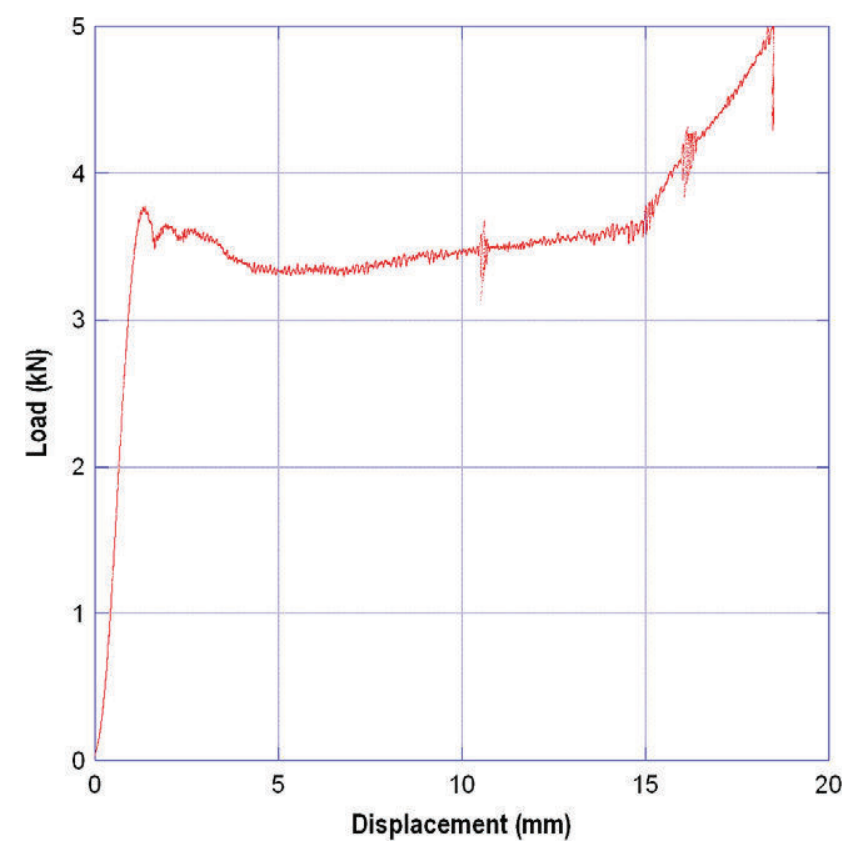

Fig. 1. Load-displacement curve for a compression test on foam core. 
Delamination:

$d_{d e l}^{2}\left(\frac{\sigma_{33}}{Z_{r}}\right)^{2}+\left(\frac{\sigma_{23}}{S_{23}}\right)^{2}+\left(\frac{\sigma_{31}}{S_{31}}\right)^{2}$

where $X_{t}$ is the strength in fibre direction; $Y_{t}$ is the strength in trans verse direction; $Z_{r}$ is strength in normal direction; $S_{12}$ is the shear strength in the fibre and transverse plane; $S_{23}$ is the shear strength in the transverse and normal plane; $S_{31}$ is the shear strength in the fibre and normal plane.

Under a given load, the stresses at each integration point in the composite structure are computed in the user subroutine. Then the failure criteria are evaluated and, if any failure occurs, the elastic

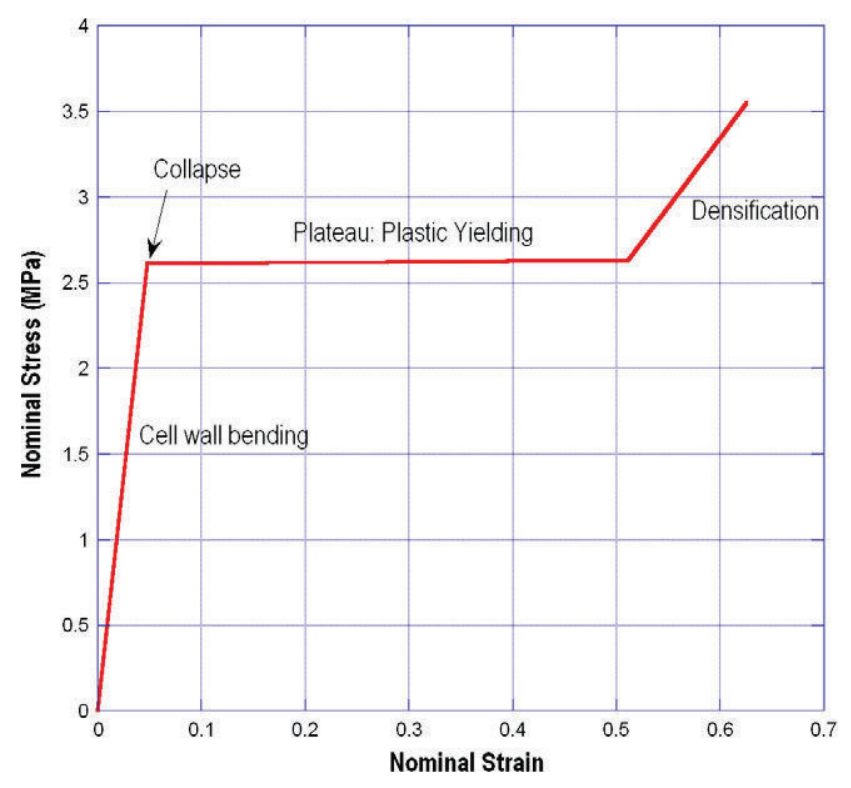

Fig. 2. Nominal stress-strain curve for a compression test on PVC foam. properties at that element must be degraded according to the mode of failure. A degradation procedure was introduced into the user subroutine to reproduce the damage to the material. When a finite element is damaged (failure criterion verified) the stresses at that element are reduced close to zero to reproduce the stiffness degradation. The stresses reduction is a numerical tool to reproduce the degradation in the material elastic properties. The updated stresses depend on the failure mode: a fibre failure pro duces the complete collapse of the material at that point $\left(\sigma_{11}=\sigma_{22}=\sigma_{33}=\sigma_{12}=\sigma_{23}=\sigma_{13}=0\right)$, whereas a delamination just avoids supporting stresses in the normal direction $\left(\sigma_{33}=\sigma_{23}=\right.$ $\sigma_{13}=0$ ).

In the dynamic bending tests, the upper face sheet was seri ously damaged. During the numerical simulations several compos ite elements were damaged, the stiffness of these elements was reduced, and therefore large deformations appeared. These dam aged elements do not contribute to the strength or the stiffness of the sandwich beam; however, they can produce instability prob lems and lack of convergence during simulation. Maximum strain criteria were included into the user subroutine to remove distorted elements: after each time increment the longitudinal strains $\left(\varepsilon_{11}\right.$, $\varepsilon_{22}$ and $\varepsilon_{33}$ ) were evaluated and the element was removed when one of them reached a critical value equal to $2 \%$.

\subsection{Core model}

The core material characterisation was developed by a foam uniaxial compression test. The hardening curve resulting from the test results, provides with the characteristic points to define the plastic behaviour of the foam core, Fig. 2. The core material was performed using the elastic properties ( $E=87 \mathrm{MPa}, v=0.3$ ) and the crushable foam plasticity behaviour defined from the uni axial compression test. Compression and hydrostatic yield stress ratios were estimated in order to define the crushable foam behaviour.

The elastic region of the stress strain curve is determined by the value of the Young's modulus. This elastic region is followed

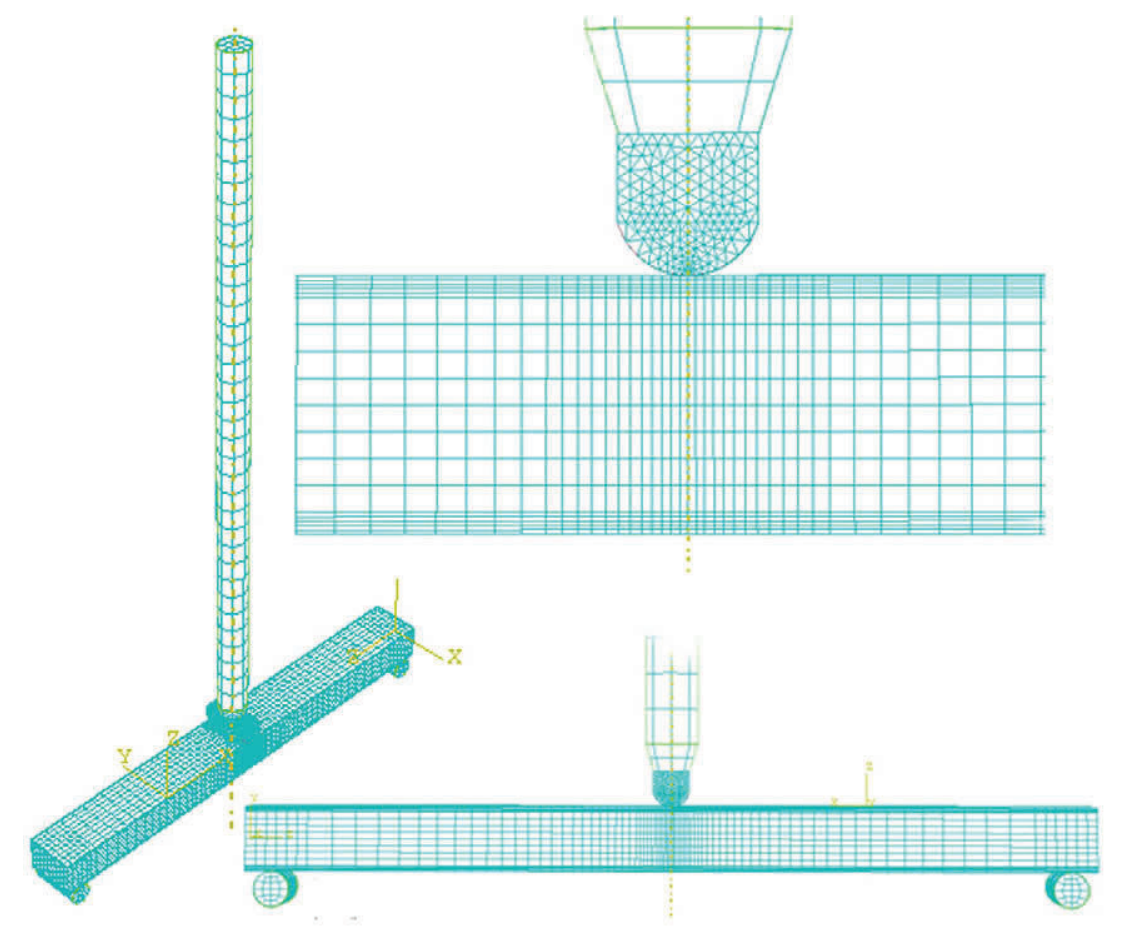

Fig. 3. Finite-element mesh used in the model. 
by a yield plateau, where the stress remains almost constant while the strain is increased. This behaviour can be described as follows: the foam materials usually consist of cells which begin to collapse when the stress reaches the yield stress. As the load continues, all the cell walls inside the foam crush together and the material be comes somewhat densified, causing the stress to increase at the last stage of the compression stress strain curve.

\subsection{Bending test model}

The dynamic bending test includes three solids (Fig. 3): sand wich beam, impactor, and support device. Since no plastic defor mation was detected after dynamic bending tests, either in the impactor or in the support device, a linear elastic behaviour was used for the steel ( $E=210 \mathrm{GPa}, v=0.3$ ). The impact energy was im posed by defining an initial velocity for the impactor. Except for the vertical movement, all impactor motions were disabled in the sim ulations, in order to ensure the normal impact over the upper face sheet. As the damage in the face sheets is located at the region in contact with the impactor, the upper ply of the glass/polyester face is usually damaged, and therefore it was necessary to define the contact between the impactor surface and a node region in the face sheets that included all the plies.

The sensitivity of the mesh was evaluated by carrying out suc cessive space discretizations; the selected mesh consisted of 18,630 elements on the impactor, the support rods, and the sand wich beam. Geometry and dimensions of the beam model were equal to those belonging to real specimens. The beam was meshed using the structured meshing technique and 13,608 8 node brick elements with reduced integration (C3D8R in ABAQUS): 6840 ele ments for both skins (composed for 5 plies each) and 5472 ele ments to define the core. The mesh was especially dense towards the impact area. The impactor model shape reproduced the most important impactor characteristics: length, mass, and nose radius. The impactor was divided into two regions: nose and stick. The nose was meshed in great detail given that it comes into contact with the upper face sheet, and thus the impactor nose mesh con sisted of 54504 node tetrahedral elements (C3D4 in ABAQUS). The stick was made up of 4288 node brick elements with reduced integration. The sandwich beam was simply supported by two rods; the FEM3D model reproduced the rod geometry using a structured hexahedral mesh. The rod mesh consisted of 2208 node brick elements with reduced integration in each rod.

\section{Dynamic tests}

Dynamic three point bending tests were performed in order to validate the finite element model. A drop weight tower, CEAST Fractovist 6785, instrumented to record the force exerted by the impactor, was used for testing 20 specimens. Sandwich beams of rectangular cross section (50 $\mathrm{mm}$ width and $36 \mathrm{~mm}$ thickness) and $480 \mathrm{~mm}$ length were tested, using a span of $450 \mathrm{~mm}$ and different impact energies between 25 and $75 \mathrm{~J}$. The impactor was a charpy nose of $20 \mathrm{~mm}$ with $7.97 \mathrm{~kg}$ of mass. The tests were recorded by a high speed video camera, measuring the impact velocity, post ricochet velocity, and the displacement in both face sheets.

\section{Model validation}

To validate the FEM3D model, the numerical results were com pared with the experimental ones. The variables used in the valida tion were the contact force history, the peak force, the maximum displacement of the upper and lower face sheets and the absorbed energy. The impact and the absorbed energies were calculated by the impactor velocities.

Numerical and experimental force histories (Fig. 4) showed a good approximation. Large oscillations appeared both in experi mental and numerical curves due to the natural frequencies of the system. The geometrical similarities between real impactor and model (nose shape, length, and diameter) produced similar natural frequencies. The peak load was estimated from contact force histories to compare the numerical and experimental peak loads at any impact energy, Fig. 5.

Both numerical and experimental peak forces were almost con stant at any impact energy, the numerical results being slightly underestimated as compared to experimental results (10.9\%). De spite the constant peak force values, the beam failed at the highest impact energies, with damage appearing in the upper face sheet, and therefore the maximum contact force was not indicative of the sandwich failure. For a better understanding of the failure pro cess, the absorbed energy as a function of impact energy is shown

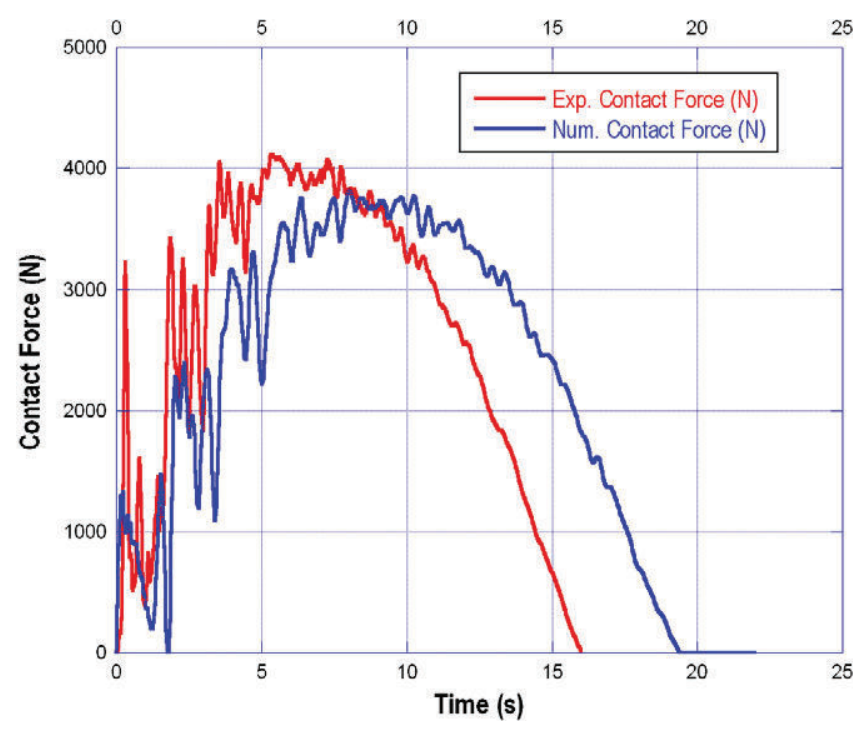

Fig. 4. Comparison between experimental and numerical contact force versus time curves. Impact energy: $36 \mathrm{~J}$.

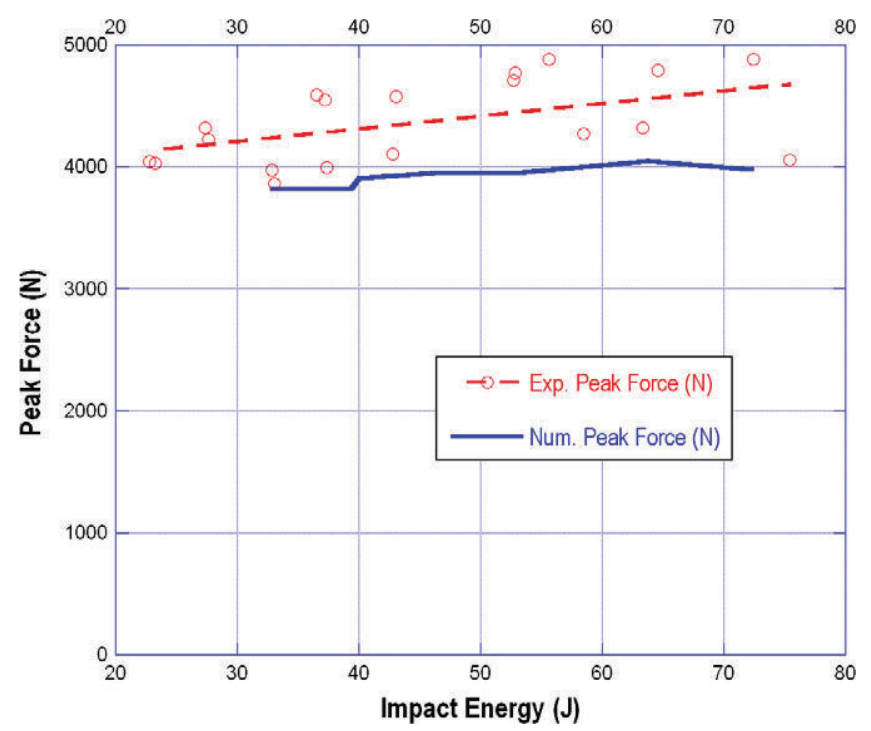

Fig. 5. Comparison between experimental and numerical peak-force values at several impact energies. 


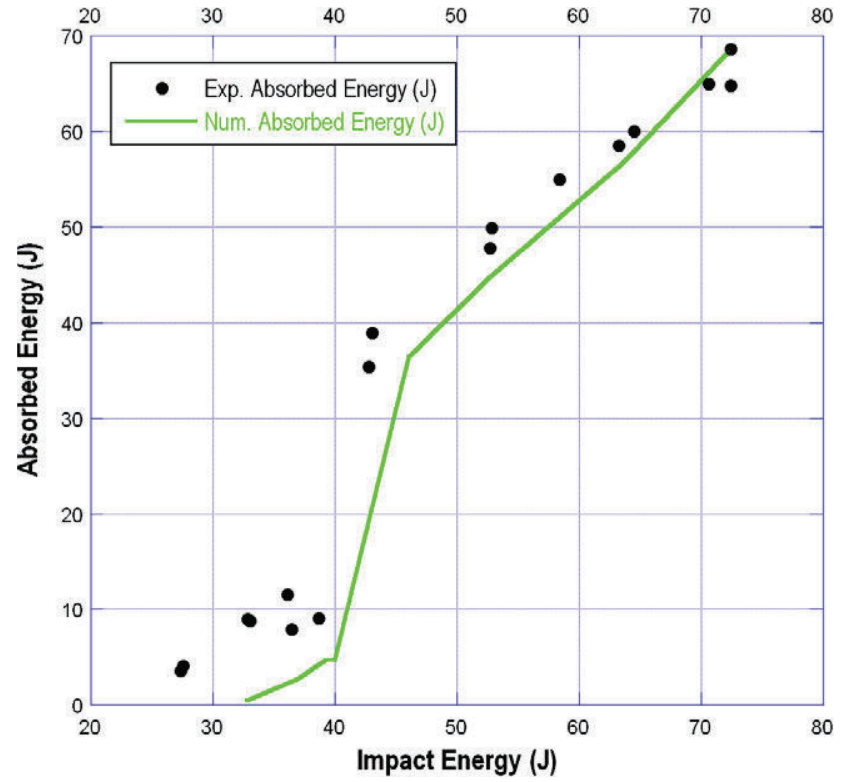

Fig. 6. Experimental and numerical absorbed energy versus impact energy.

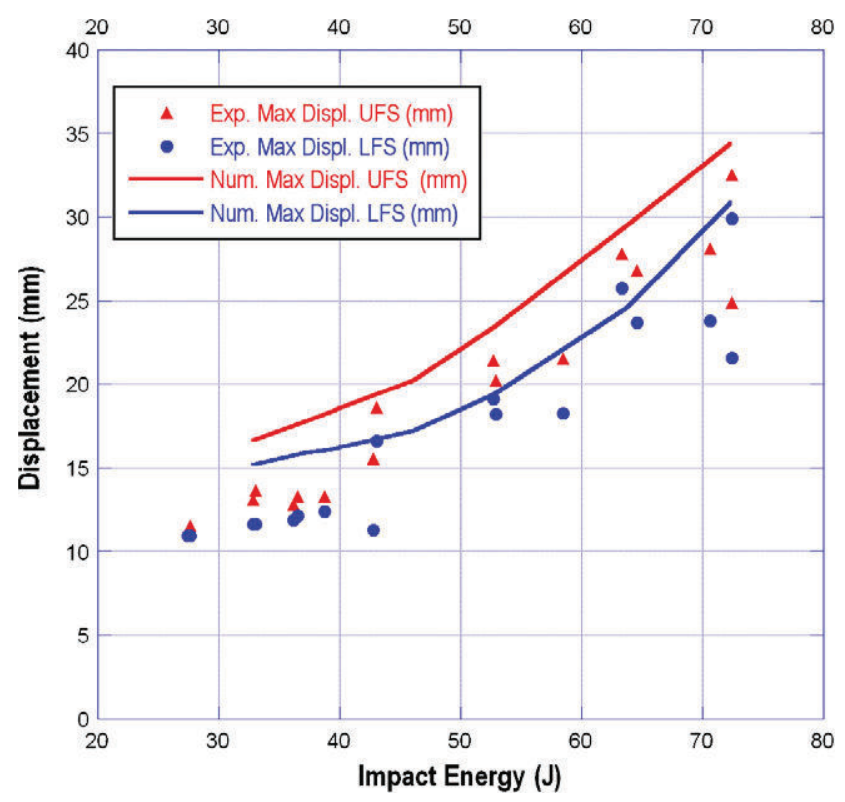

Fig. 7. Comparison between numerical and experimental upper and lower facesheets maximum displacements. in Fig. 6. Two regions can be distinguished: for lower impact ener gies, below $40 \mathrm{~J}$, the absorbed energy was very low, whereas, for higher impact energies, above $40 \mathrm{~J}$, the absorbed energy was higher because the sandwich beam failed. Higher energy absorption lev els are caused by the failure of the upper face sheet; however, the absorbed energy increased with the increment of the impact energy, which indicated a contribution of the foam core in the en ergy absorption process. Both experimental and numerical curves followed the same trend and the results were very similar, demon strating that the numerical model is capable of accurately predict ing the dynamic flexural response of sandwich beams.

The maximum displacements of upper and lower face sheets determined with the numerical model were compared with the experimental ones (Fig. 7). The numerical and experimental dis placements of upper and lower face sheets increased with the ris ing impact energy. The difference between the displacements of upper and lower face sheets was more noticeable at higher im pact energy levels because the upper face sheet had failed. For lower impact energies, below $40 \mathrm{~J}$, the displacements of upper and lower face sheets were similar and no local strains were found. There was good agreement between experimental and numerical results in terms of values and trend, the numerical ones being slightly higher.

The numerical results were quite close to the experimental ones and the numerical model could reproduce the failure of the sand wich beams (Fig. 8), so that the model was used to gather more information than that provided by experimental tests and to gain a better understanding of the failure process of a composite sand wich beam.

\section{Analysis of sandwich beam failure}

The validated FEM3D model was used to analyse the main fail ure mechanisms of the composite sandwich beams. Fig. 9 shows the fields of the different face sheets fibre failure criteria and the field of displacements just before beam failure.

Just before the failure of the beam, the displacement of the upper face sheet was substantially higher than that observed in the lower face sheet due to a collapse of the foam core below the contact zone, Fig. 9(a). This collapse of the core produced a high deflection in the upper face sheet and a great curvature in the composite layers. In the most deflected region of the upper face sheet, the values pertaining to the failure criteria (fibre failure in fibre and transverse directions, and delamination) were close to unity, and therefore the mechanical properties were degraded and the composite layers failed (Fig. 8). The values of the failure criteria in the lower face sheet were close to zero, so the high stress levels found in the upper face sheet were caused by the col lapse of the foam core.

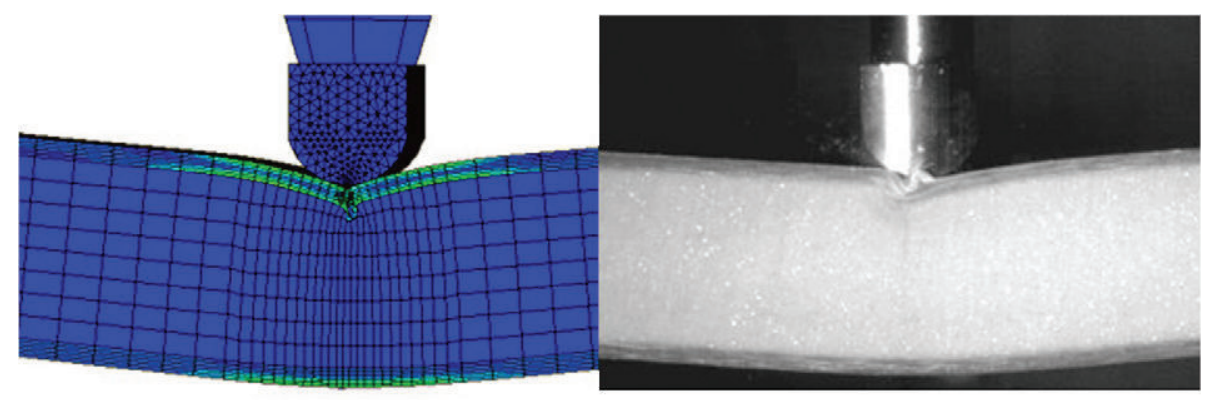

(a)

(b)

Fig. 8. Deformation of the sandwich beam at impact energy $52 \mathrm{~J}$ : (a) finite-element model, (b) experimental test. 


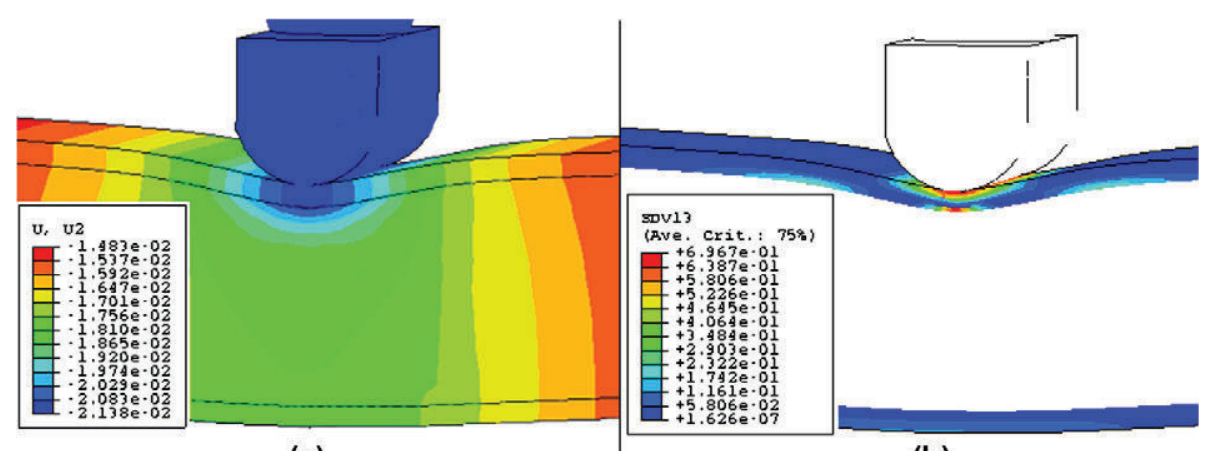

(a)

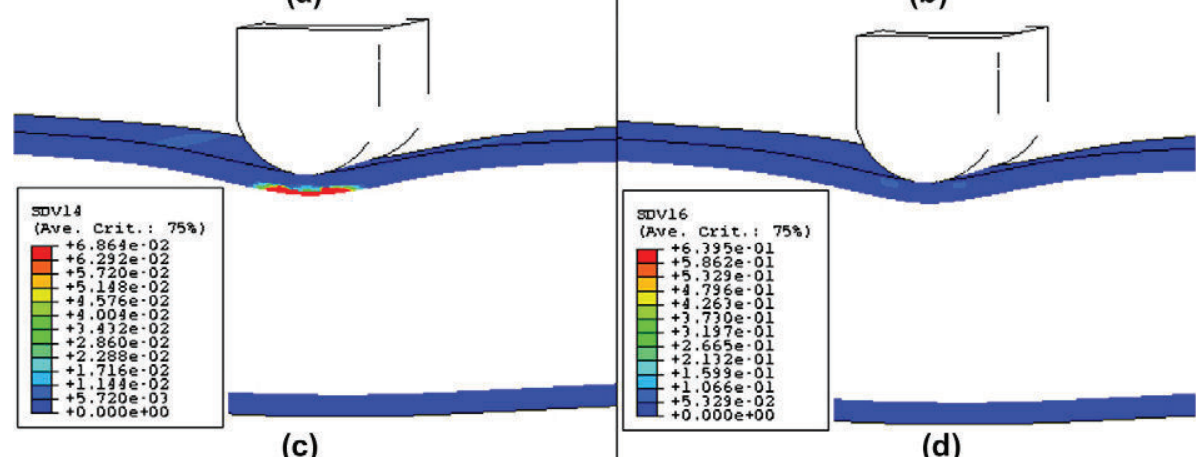

(c)

\section{(d)}

Fig. 9. Failure mechanisms for crushable foam-core sandwich beams at impact energy 52 J (just before failure): (a) displacements, (b) fibre-failure (fibre direction) criterion, (c) fibre-failure (transverse direction) criterion, (d) delamination.

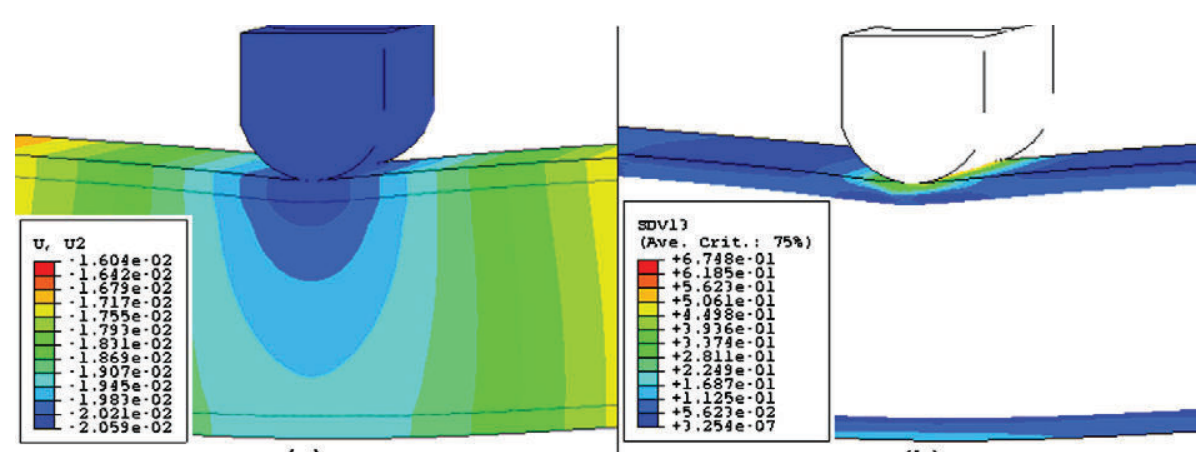

(a)

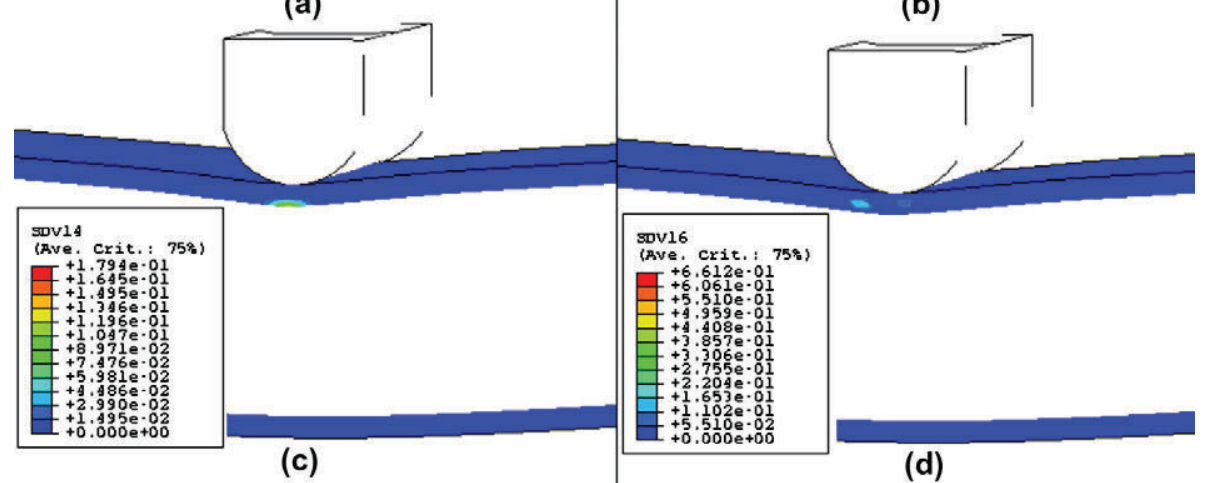

Fig. 10. Failure mechanisms for non-crushable foam-core sandwich beams at impact energy $52 \mathrm{~J}$ : (a) displacements, (b) fibre-failure (fibre direction) criterion, (c) fibre-failure (transverse direction) criterion, (d) delamination.

For a better understanding of the failure mechanisms of a foam core sandwich beam, a model with a non crushable core and linear elastic behaviour was developed. The elastic properties were the same as those used for the crushable foam model. The results for this core without crushing behaviour were quite differ ent (Fig. 10). As the core did not collapse near the contact zone, the deflection of the upper face sheet was similar to that observed in the lower one, so that the values of the failure criteria were lower and the face sheet did not fail. The compressive behaviour of the foam core determined the failure of the sand wich beam despite the higher strength of the composite face sheets. 


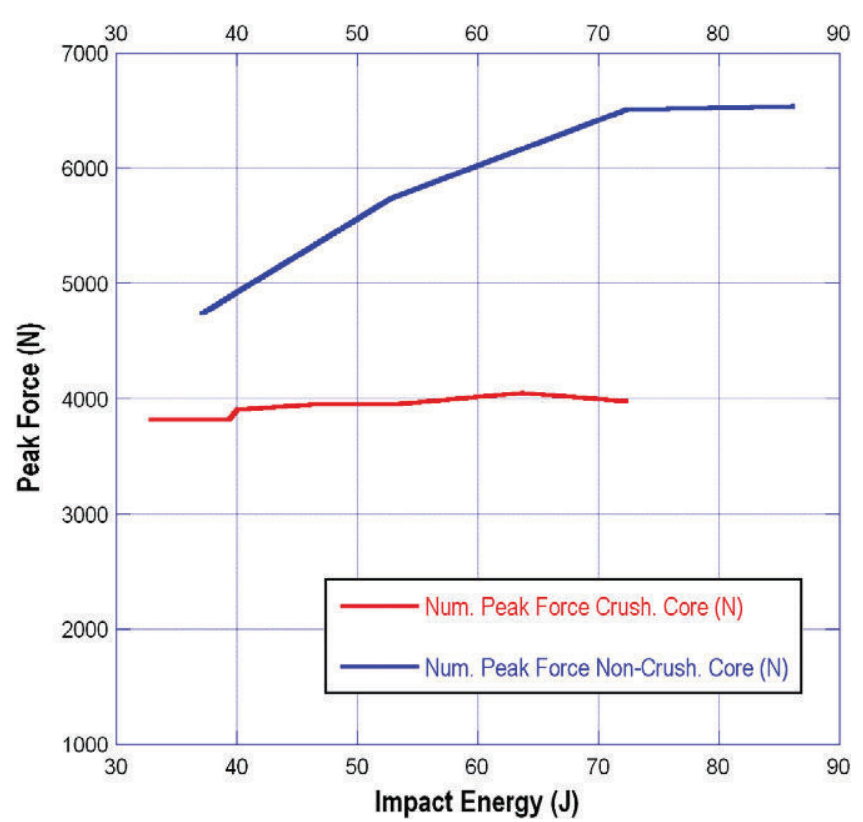

Fig. 11. Peak-force versus impact energy: comparison between non-crushable foam-core beams and crushable foam-core beams (numerical results).

The model with the non crushable core presented a higher resistance to low velocity impacts; the failure of the sandwich beam did not occur for impact energy lower than $85 \mathrm{~J}$. The peak force increased with the impact energy whereas it was almost con stant in the crushable foam model (Fig. 11).

\section{Conclusions}

The dynamic behaviour of composite sandwich beams was modelled by performing a 3D finite element dynamic three point bending test simulation. To analyse the composite face sheet behaviour, a progressive failure damage model based on Hou fail ure criteria was included. The foam core was modelled using the crushable foam hardening plasticity model.

The accuracy of the finite element model was determined by comparing experimental results with numerical predictions at sev eral impact energies in terms of contact force histories, peak force, maximum displacements of upper and lower face sheets, and ab sorbed energy. Agreement with the experimental results was satis factory, and thus the model accurately represents the dynamic flexural behaviour of sandwich beams.

In addition, damage evolution and failure mechanisms of the sandwich beams were studied. It was found that the collapse of the foam core under the impact region favoured the failure of the composite upper face sheet because of its high deflection and the resulting great curvature. For a better understanding of this phe nomenon, a model with non crushable foam was simulated. In this case, the core collapse and the deflection of the upper face sheet were lower than in the crushable foam model. The failure of the non crushable core sandwich beams did not occur at impact ener gies below $85 \mathrm{~J}$, whereas the impact energy to cause the failure of these beams with the crushable foam core was approximately $40 \mathrm{~J}$. Thus, the compressive behaviour of the foam core significantly determines the failure of the sandwich beams despite the high strength of the composite face sheets.

\section{Acknowledgement}

The authors are indebted to the Autonomous Community of Madrid and University Carlos III of Madrid (Project CCG08 UC3M/ DPI 4348) for the financial support of this work.

\section{References}

[1] Sanchez-Saez S, Barbero E, Navarro C. Analysis of the dynamic flexura behaviour of composite beams at low temperature. Compos Sci Technol 2007;67:2616-32.

[2] Santiuste C, Sanchez-Saez S, Barbero E. Application of the flexibility influence function method in the dynamic analysis of composite beams. Int J Solids Struct 2007:44(14-15):4795-809.

[3] Santiuste C, Sanchez-Saez S, Barbero E. Dynamic analysis of bending-torsion coupled composite beams using the flexibility influence function method. Int J Mech Sci 2008;50(12):1611-8.

[4] Mines RAW, Alias A. Numerical simulation of the progressive collapse of polymer composite sandwich beams under static loading. Compos Part A Appl Sci 2002;33:11-26.

[5] Steeves CA, Fleck NA. Collapse mechanism of sandwich beams with composite faces and a foam core, loaded in three-point bending. Part II: experimental investigation and numerical modelling. Int J Mech Sci 2004;46:585-608.

[6] Tagarielli VL, Fleck NA, Deshpande VS. Collapse of clamped and simply supported composite sandwich beams in three-point bending. Compos Part B Eng 2004;35:523-34.

[7] Zenkert D, Shipsha A, Persson K. Static indentation and unloading response of sandwich beams. Compos Part B - Eng 2004;35:511-22.

[8] Shahdin A, Mezeix L, Bouvet C, Morlier J, Gourinat Y. Fabrication and mechanical testing of glass fiber entangled sandwich beams: a comparison with honeycomb and foam sandwich beams. Compos Struct 2009. doi:10.1016/j.compstruct.2009.04.003.

[9] Abrate S. In: Impact on composite structures. Cambridge University Press; 1998.

[10] Caprino G, Teti R. Impact and post-impact behavior of foam core sandwich structures. Compos Struct 1994;29(1):47-55.

[11] Anderson T, Madenci E. Experimental investigation of low-velocity impact characteristics of sandwich composites. Compos Struct 2000:50:239-47.

[12] Hazizan MA, Cantwell WJ. The low velocity impact response of foam-based sandwich structures. Compos Part B - Eng 2002;33:193-204.

[13] Tagarielli VL, Deshpande VS, Fleck NA. The dynamic response of composite sandwich beams to transverse impact. Int J Solids Struct 2007:44:2442-57.

[14] Mines RAW, Worrall CM, Gibson AG. The static and impact behaviour of polymer composite sandwich beams. Composites 1994;2:95-110.

[15] Sadighi M, Pouriayevali H. Quasi-static and low-velocity impact response of fully backed or simply supported sandwich beams. J Sandwich Struct Mater 2008;10:499-524.

[16] Icardi U, Ferrero L. Impact analysis of sandwich composites based on a refined plate element with strain energy updating. Compos Struct 2009;89:35-51.

[17] Chang F, Chang KA. A progressive damage model for laminated composites containing stress concentrations. J Compos Mater 1987;21:834-55.

[18] Hou JP, Petrinic N, Ruiz C, Hallet SR. Prediction of impact damage in composite plates. Compos Sci Technol 2000;60:445-50.

[19] Lopez-Puente J, Zaera R, Navarro C. High energy impact on woven laminates. J Phys IV 2003;110:639-44.

[20] Garcia-Castillo SK, Sanchez-Saez S, Lopez-Puente J, Barbero E, Navarro C. Impact behaviour of preloaded glass/polyester woven plates. Compos Sci Technol 2009;69(6):711-7.

[21] Deshpande VS, Fleck NA. Multi-axial yield behaviour of polymer foams. Acta Mater 2001;49:1859-66.

[22] Hibbit, Karlsson \& Sorensen, Inc. ABAQUS/Explicit user's manual, Version 6.4.

[23] Brewer JC, Lagace PA. Quadratic stress criterion for initiation of delamination. J Compos Mater 1988;22:1141-55. 